\title{
Pengaruh Pupuk NPK Majemuk terhadap N-Total, Serapan N, dan Hasil Umbi Bawang Merah (Allium ascalonicum L.) pada Inceptisols Asal Jatinangor
}

\author{
Shindy Widiana1), Anni Yunarti2), Emma Trinurani Sofyan'2), Dirga Sapta Sara') \\ 1)Program Studi Agroteknologi, Fakultas Pertanian Universitas Padjadjaran \\ 2)Departemen Ilmu Tanah dan Sumberdaya Lahan, Fakultas Pertanian Universitas Padjadjaran \\ Jl. Raya Bandung Sumedang Km 21 Jatinangor \\ Korespondensi: shindywidianaa@gmail.com
}

\begin{abstract}
Shallot (Allium ascalonicum L.) is a horticulture commodity that has a lot of benefits and also prospective due its increasing demand. Annual shallot productivity in Indonesia is unstable due to nutrient degradation on agricultural land, therefore efforts are needed to promote the productivity of shallot. One of the solution using NPK fertilization. This experiment aimed to determine the effect of $N P K$ compound fertilizer on $N$ total, $N$-uptake, and shallot bulb yield. This research conducted at the Soil Chemical and Plant Nutrition Experiments Field, Faculty of Agriculture, Padjadjaran University, Jatinangor, from February to June 2019. The experimental design used was Randomized Block Design (RBD) consisted of one control treatment, one $N, P, K$ single fertilizer treatment (250 kg ha-1 Urea, 125 $\mathrm{kg} \mathrm{ha}^{-1} \mathrm{ZA}, 200 \mathrm{~kg} \mathrm{ha}^{-1} \mathrm{SP}-36$, and $250 \mathrm{~kg} \mathrm{ha}^{-1} \mathrm{KCl}$ ), and eight NPK compound fertilizer treatments in various doses with three replications. The results showed that the NPK compound treatment affected the total $N$, $N$ uptake, and shallot bulbs yield. Treatment of 75\% NPK compound ( $675 \mathrm{~kg} \mathrm{ha}^{-1}$ ) gave the highest results of fresh bulbs weight at $41.64 \mathrm{~g} / \mathrm{clump}$ and dry bulbs weight at $25.27 \mathrm{~g} / \mathrm{clump}$.
\end{abstract}

Keywords: Inceptisols, NPK Compound, N Total, N-uptake, Shallot.

\section{PENDAHULUAN}

Bawang marah merupakan komoditi hortikultura yang memiliki banyak manfaat diantaranya sebagai pelengkap bumbu masakan untuk menambah citarasa masakan serta sebagai bahan obat tradisional. Bawang merah (Allium ascalonicum L.) yang termasuk ke dalam famili Liliaceae dapat diperbanyak secara generatif menggunakan biji, maupun secara vegetatif menggunakan umbi (Balai Penelitian Tanaman Sayuran, 2018). Tanah yang gembur, subur, banyak mengandung bahan organik atau humus sangat baik untuk bawang merah. Tanah yang demikian akan mendorong perkembangan umbi sehingga hasilnya besar-besar (Purnawanto dan Budi, 2018).

Produksi bawang merah setiap tahunnya cenderung meningkat, namun produktivitas bawang merah masih belum stabil. Pada tahun 2014 produktivitas bawang merah sebesar 10,22 t/ha, pada tahun 2015 produktivitas bawang merah sebesar 10,06 t/ha, pada tahun 2016 produksi bawang merah sebesar 9,67 t/ha, pada tahun 2017 produktivitas bawang merah sebesar 9,31 t/ha, dan pada tahun 2018 produktivitas bawang merah sebesar 9,59 t/ha (Badan Pusat Statistik, 2018). Penurunan produktivitas bawang merah ini dapat disebabkan oleh degradasi tanah pertanian yang menyebabkan penanaman bawang merah dilakukan pada lahan memiliki tingkat ketersediaan unsur hara yang relatif rendah (Napitupulu dan Winarto, 2010)

Trisula merupakan varietas bawang merah yang dapat beradaptasi dengan baik di daerah dataran rendah dengan ketinggian 6-85 m. Bentuk umbi bulat berwarna merah tua, jumlah umbi per rumpun berkisar antara 5-8 umbi dengan berat umbi 39-93,3 g per rumpun. Potensi produktivitas bawang merah varietas Trisula dapat mencapai 23,21 ton/ha. (Kementrian Pertanian, 2011; Balai Penelitian Tanaman Sayuran, 2018). Produktivitas yang tinggi perlu didukung dengan teknik budidaya yang tepat, salah satunya adalah pemupukan.

Inceptisols merupakan ordo tanah dengan sebaran yang cukup luas di Indonesia. Karakteristik ordo tanah ini diantaranya: solum tanahnya agak tebal (1- >2 m), tanahnya berwarna hitam atau kelabu hingga coklat tua, tingkat kemasaman (pH) 5,0 - 7,0, kadar bahan 
organik $<20 \%$. Sebagian besar Inceptisol di Indonesia memiliki tingkat kesuburan yang rendah, hal ini dikarenakan $\mathrm{pH}$ tanah yang masam, tingkat pencucian hara yang tinggi, dan kadar liat tinggi (Fiantis, 2014). Upaya meningkatkan kesuburan tanah Inceptisol dapat dilakukan dengan penambahan bahan organik dan pemupukan yang berimbang.

Pemberian pupuk merupakan salah satu upaya dalam memperbaiki permasalahan kesuburan tanah melalui penambahan unsur hara. Ketersediaan unsur hara bagi tanaman selama pertumbuhan sangat diperlukan, karena ketersediaan unsur hara merupakan syarat utama dalam meningkatkan produksi tanaman. Penambahan unsur hara ini akan memperbaiki serapan hara yang menunjang pertumbuhan tanaman (Novizan, 2005). Salah satu cara penambahan unsur hara secara lengkap adalah dengan pemberian pupuk majemuk. Pupuk majemuk mempunyai kandungan berupa hara makro N, P dan K yang tidak dimiliki pupuk tunggal dan lebih praktis pengaplikasiannya (Damanik dkk., 2010).

Pemberian pupuk majemuk yang mengandung $\mathrm{N}, \mathrm{P}$ dan $\mathrm{K}$ dapat menunjang pertumbuhan dan produksi bawang merah. Dosis pupuk majemuk NPK berpengaruh nyata terhadap bobot kering daun bawang (Istina, 2016). Hal ini dipengaruhi oleh peranan nitrogen dalam memacu pertumbuhan vegetatif. Nitrogen merupakan unsur hara yang penting pada tanaman semusim termasuk bawang merah. Nitrogen digunakan sebagai energi pertumbuhan tanaman untuk membentuk organ vegetatif seperti daun dan batang (Napitupulu dan Winarto, 2010). Efisiensi pemupukan dapat dinilai melalui serapan hara pada tanaman (Roosmarkam dan Yuwono, 2002). Peningkatan serapan $\mathrm{N}$ berpengaruh nyata terhadap penambahan tinggi tanaman dan bobot kering tanaman bawang (Sumarni dkk., 2012).

Berdasarkan uraian yang telah dipaparkan, maka perlu dilakukan penelitian tentang pengaruh pupuk NPK majemuk terhadap Ntotal, serapan $\mathrm{N}$, dan hasil umbi bawang merah pada Inceptisols asal Jatinangor.

\section{METODOLOGI}

Percobaan ini dilaksanakan di Kebun Percobaan Laboratorium Kimia Tanah dan Nutrisi Tanaman, Fakultas Pertanian, Universitas Padjadjaran. Tempat percobaan berada pada ketinggian $\pm 752 \mathrm{~m} \mathrm{dpl}$. Analisis $\mathrm{N}$-total dan serapan $\mathrm{N}$ dilaksanakan di Laboratorium Kimia Tanah dan Nutrisi Tanaman, Fakultas Pertanian, Universitas Padjadjaran, Jatinangor. Percobaan ini dilaksanakan pada bulan Februari hingga Juni 2019.

\subsection{Rancangan Percobaan}

Rancangan yang digunakan pada percobaan ini adalah Rancangan Acak Kelompok (RAK). Perlakuan disusun sebanyak 10 perlakuan yang terdiri atas:

A : Kontrol (tanpa pupuk NPK, tanpa pupuk $\mathrm{N}, \mathrm{P}, \mathrm{K}$ tunggal, tanpa pupuk organik)

B : N, P, K tunggal $(250 \mathrm{~kg} /$ ha Urea, 125 $\mathrm{kg} / \mathrm{haZA}, 200 \mathrm{~kg} / \mathrm{ha}$ SP-36, dan $250 \mathrm{~kg} / \mathrm{ha}$ $\mathrm{KCl}$ )

C : Pupuk NPK 25\% (225 kg/ha)

D : Pupuk NPK 50\% (450 kg/ha)

E : Pupuk NPK 75\% (675 kg/ha)

F : Pupuk NPK 100\% (900 kg/ha)

G : Pupuk NPK 125\% (1.125 kg/ha)

H : Pupuk NPK 150\% (1.350 kg/ha)

I : $50 \% \mathrm{NPK}(450 \mathrm{~kg} / \mathrm{ha})+50 \% \mathrm{~N}, \mathrm{P}, \mathrm{K}$ tunggal (125 kg/ha Urea, $62,5 \mathrm{~kg} / \mathrm{ha} \mathrm{ZA}$, $100 \mathrm{~kg} / \mathrm{ha} \mathrm{SP}-36$, dan $125 \mathrm{~kg} / \mathrm{ha} \mathrm{KCl)}$

J : 75\% Pupuk NPK (675 kg/ha) + 75\% N, P, K tunggal $(187,5 \mathrm{~kg} / \mathrm{ha}$ Urea, $93,75 \mathrm{~kg} / \mathrm{ha}$ ZA, $150 \mathrm{~kg} / \mathrm{ha}$ SP-36, dan 187,5 kg/ha $\mathrm{KCl}$ )

Masing-masing perlakuan diulang tiga kali, sehingga terdapat 30 satuan percobaan. Masing-masing satuan percobaan berupa petakan berukuran 150 x $200 \mathrm{~cm}$.

\subsection{Penanaman}

Persiapan bibit bawang merah dilakukan sebelum penanaman. Bibit yang digunakan merupakan bibit yang telah berumur tua (70 atau 80 HST). Bibit yang digunakan telah diseleksi baik dilapangan maupun di tempat penyimpanan dengan keadaan umbi utuh, warna umbi mengkilap, bebas dari organisme 
pengganggu tanaman (sehat). Umbi yang digunakan berukuran sedang berdiameter 1,5$2 \mathrm{~cm}$ dengan bentuk simetris.

Sebelum ditanam, umbi terlebih dahulu dipotong ujungnya kurang lebih $1 / 4$ bagian umbi. Hal ini bertujuan agar pertumbuhan umbi merata, merangsang pertumbuhan tunas, mempercepat tumbuhnya tanaman, dan dapat mendorong terbentuknya anakan (Jumini dkk., 2010). Sebelum ditanam, kulit luar umbi dan sisa-sisa akarnya dibersihkan.

Penanaman dilakukan dengan cara memasukkan 1 buah umbi dalam 1 lubang tanam, jarak tanam yang digunakan adalah $20 \times 15 \mathrm{~cm}$. Jumlah populasi tanaman bawang merah per petak percobaan adalah 100 tanaman.

\subsection{Pemupukan, Pemeliharaan Tanaman, dan Pemanenan}

Pupuk yang digunakan pada percobaan ini yaitu pupuk organik kompos kotoran sapi sebanyak $2 \mathrm{t} /$ ha yang diberikan sebelum tanam pada semua perlakuan sebagai pupuk dasar. Pemberian pupuk NPK (perlakuan) dilakukan dengan cara sideband atau di samping tanaman dengan membuat lubang kemudian lubang ditutup kembali dengan tanah.

Pupuk N, P, dan K tunggal diberikan pada perlakuan $\mathrm{B}(\mathrm{N}, \mathrm{P}, \mathrm{K}$ tunggal), perlakuan I (50\% NPK dan $50 \%$ N, P, K tunggal), dan perlakuan J (75\% NPK dan 75\% N, P, K tunggal) yang terdiri dari SP-36 $\left(36 \% \mathrm{P}_{2} \mathrm{O}_{5}\right), \mathrm{KCl}\left(60 \% \mathrm{~K}_{2} \mathrm{O}\right)$, Urea $(45 \% \mathrm{~N})$, dan ZA (21\% N, 24\% S), serta pupuk NPK dengan rasio 15-9-20 untuk perlakuan lainnya. Pupuk SP-36 dan $\mathrm{KCl}$ diberikan seluruhnya pada saat tanam, sedangkan pemupukan urea dan ZA dibagi menjadi $1 / 2$ dosis yang diberikan saat tanaman bawang merah berumur 14 HST dan 34 HST. Pupuk NPK diberikan saat tanaman berumur 10, 21, dan 35 HST.

Pemeliharaan yang dilakukan pada percobaan ini mengacu pada pemeliharaan standar yang dilaksanakan pada budidaya tanaman bawang merah. Pemeliharaan tersebut berupa penyiraman, penyulaman, pengendalian gulma, serta pencegahan atau pengendalian hama dan penyakit. Penyiraman dilakukan setiap hari pada pagi dan sore hari yang bertujuan agar tanaman terhindar dari kekeringan serta untuk menjaga kelembaban tanah. Penyiraman dilakukan sampai kondisi media tanam dalam kondisi lembab. Jika terjadi hujan penyiraman tidak dilakukan karena tanah sudah dalam keadaan lembab.

Penyulaman dilakukan untuk mengganti tanaman yang mati, kegiatan ini dilakukan dengan mengambil tanaman pada saat kurang dari 14 HST dari perlakuan yang sama dengan sampel cadangan yang telah disediakan supaya tanaman dapat tumbuh pada kondisi media yang sama. Pengendalian hama penyakit dilakukan secara fisik maupun kimiawi. Pengendalian hama secara fisik adalah dengan mengambil hama secara langsung yang telihat dilokasi pengujian. Pengendalian hama secara kimiawi adalah dengan menyemprotkan insektisida Antracol 70 WP berbahan aktif frofenofos pada tanaman yang terkena serangga. Pengendalian penyakit hanya dilakukan secara kimiawi dengan menyemprotkan fungsisida Demolish 18 EC berbahan aktif abamektin dengan konsentrasi $2 \mathrm{cc} / \mathrm{L}$ pada tanaman yang terkena hawar daun dilahan pengujian.

Bawang merah dipanen setelah umurnya cukup tua yaitu pada umur 60 HST apabila terlihat tanda-tanda $60 \%$ leher batang lunak, tanaman rebah, dan daun menguning. Pemanenan dilakukan pada saat keadaan tanah kering dan cuaca yang cerah. Hal tersebut dilakukan agar umbi yang telah dipanen terhindar dari serangan busuk umbi yang akan menurunkan kualitas dan kuantitas umbi.

\subsection{Pengambilan Sample Tanaman dan \\ Tanah}

Pengambilan sampel tanah dan tanaman dilakukan saat tanaman memasuki fase vegetatif maksimum dengan tanda keluarnya bunga yaitu pada umur 42 HST. Sample tanah diambil dari daerah sekitar perakaran tanaman (rhizosfer) pada saat 42 HST. Tanah diambil dari 5 titik sampel secara diagonal pada setiap perlakuan, lalu dikompositkan. Sample tanah kemudian dimasukkan ke dalam kantung 
plastik bening sebanyak $\pm 500 \mathrm{~g}$ dan diberi label sesuai perlakuan.

Sampel tanaman diambil dengan memotong seluruh brangkasan daun bawang merah dari permukaan tanah sampai ujung tajuk umbi bawang merah yang diambil dari lima titik sampel tanaman dengan pola membentuk mata dadu 5. Sample tanaman segar ditimbang dan dimasukkan ke dalam amplop berwarna cokelat, kemudian dikeringkan menggunakan oven selama \pm 7 hari. Setelah kering daun dihaluskan sampai berukuran 0,5 mm, kemuadian dimasukkan ke dalam kantung plastik bening dan diberi label sesuai perlakuan. Sample ini digunakan untuk analisis serapan $\mathrm{N}$ di laboratorium. Pengujian $\mathrm{N}$-total dianalisis dengan menggunakan metode Kjeldahl.

\subsection{Analisis Data}

Analisis data dilakukan dengan menggunakan aplikasi Statistical Package for the Social Sciences (SPSS) versi 16. Pengujian perbedaan pengaruh rata-rata perlakuan dilakukan dengan metode uji $\mathrm{F}$ pada taraf kepercayaan 95\% apabila terdapat pengaruh yang nyata maka dilakukan dengan uji lanjut jarak berganda (Multiple Range Test) Duncan pada taraf nyata $5 \%$.

\section{HASIL DAN PEMBAHASAN}

\subsection{Kadar N-total}

Hasil analisis statistik terhadap kadar Ntotal menunjukkan bahwa pemberian pupuk NPK majemuk berpengaruh terhadap N-total tanah. Berdasarkan data pada Tabel 1 perlakuan pupuk NPK majemuk $75 \%$ menghasilkan $\mathrm{N}$-total yang nyata lebih tinggi dibandingkan perlakuan lainnya, dengan ratarata $0,21 \%$.

Perlakuan pupuk NPK majemuk 150\% menghasilkan $\mathrm{N}$-total yang tidak berbeda nyata dibandingkan perlakuan lain selain perlakuan pupuk NPK majemuk 75\% dan perlakuan kontrol. Hal tersebut menunjukkan bahwa penggunaan pupuk anorganik dalam jumlah yang banyak, tidak berpengaruh terhadap peningkatan $\mathrm{N}$-total dalam tanah. Pemberian pupuk $\mathrm{N}$ berlebih dapat mening-katkan tingkat kehilangan N (Xiang et. al., 2008).

Tabel 1 Pengaruh pupuk NPK majemuk terhadap N-Total

\begin{tabular}{|c|c|c|}
\hline & Perlakuan & $\begin{array}{c}\mathrm{N} \text {-total } \\
(\%)\end{array}$ \\
\hline A & Kontrol & $0,13 \mathrm{a}$ \\
\hline B & Pupuk N, P, K standar & $0,17 \mathrm{~b}$ \\
\hline $\mathrm{C}$ & $25 \%$ dosis pupuk NPK majemuk & $0,17 \mathrm{~b}$ \\
\hline $\mathrm{D}$ & $50 \%$ dosis pupuk NPK majemuk & $0,17 \mathrm{~b}$ \\
\hline E & 75\% dosis pupuk NPK majemuk & $0,21 \mathrm{c}$ \\
\hline $\mathrm{F}$ & $\begin{array}{l}100 \% \text { dosis pupuk NPK } \\
\text { majemuk }\end{array}$ & $0,18 \mathrm{~b}$ \\
\hline G & $\begin{array}{l}125 \% \text { dosis pupuk NPK } \\
\text { majemuk }\end{array}$ & $0,17 \mathrm{~b}$ \\
\hline $\mathrm{H}$ & $\begin{array}{l}150 \% \text { dosis pupuk NPK } \\
\text { majemuk }\end{array}$ & $0,17 \mathrm{~b}$ \\
\hline I & $\begin{array}{l}50 \% \text { dosis pupuk NPK majemuk } \\
+50 \% \text { dosis N, P, K tunggal }\end{array}$ & $0,17 \mathrm{~b}$ \\
\hline $\mathrm{J}$ & $\begin{array}{l}75 \% \text { dosis pupuk NPK majemuk } \\
+75 \% \text { dosis N, } \mathrm{P}, \mathrm{K} \text { tunggal }\end{array}$ & $0,17 \mathrm{~b}$ \\
\hline \multicolumn{3}{|c|}{$\begin{array}{l}\text { Keterangan: Angka yang diikuti dengan huruf yang } \\
\text { sama tidak menunjukkan perbedaan } \\
\text { yang nyata menurut uji jarak berganda } \\
\text { Duncan taraf } 5 \% .\end{array}$} \\
\hline
\end{tabular}

\subsection{Serapan N}

Hasil analisis terhadap serapan $\mathrm{N}$ menunjukkan pupuk NPK majemuk berbeda nyata dengan kontrol. Berdasarkan Tabel 2, perlakuan pupuk NPK majemuk 75\% memiliki serapan $\mathrm{N}$ yang paling tinggi yaitu $40,76 \mathrm{mg} /$ tanaman, sedangkan serapan $\mathrm{N}$ terendah ada pada perlakuan kontrol yaitu 20,31 mg/ tanaman. Perlakuan pupuk NPK majemuk 75\% menunjukkan perlakuan yang memberikan hasil serapan $\mathrm{N}$ paling tinggi jika dibandingkan perlakuan lainnya.

Hal ini dikarenakan tanaman akan maksimal dalam menyerap $\mathrm{N}$ sesuai dengan kapasitasnya. Hal ini menunjukkan bahwa tanaman bawang merah menyerap unsur hara N lebih optimal pada dosis NPK majemuk $75 \%$ dibandingkan perlakuan yang lainnya. Aplikasi $\mathrm{N}$ yang berlebih tidak meningkatkan perkembangan tanaman, justru akan menurunkan efisiensi penyerapannya (Hedge, 1988 dalam 
Natitupulu dan Winarto, 2010; Hartatik dan Adiningsih, 2003).

Tabel 2 Pengaruh pupuk NPK majemuk terhadap serapan $\mathrm{N}$

\begin{tabular}{|c|c|c|}
\hline \multicolumn{2}{|c|}{ Perlakuan } & \multirow{2}{*}{$\begin{array}{c}\begin{array}{c}\text { Serapan N } \\
(\mathrm{mg} / \text { tanaman })\end{array} \\
20,31 \mathrm{a}\end{array}$} \\
\hline $\mathrm{A}$ & Kontrol & \\
\hline B & Pupuk N, P, K standar & $34,12 \mathrm{~cd}$ \\
\hline $\mathrm{C}$ & $\begin{array}{l}25 \% \text { dosis pupuk NPK } \\
\text { majemuk }\end{array}$ & $22,15 \mathrm{ab}$ \\
\hline $\mathrm{D}$ & $\begin{array}{l}50 \% \text { dosis pupuk NPK } \\
\text { majemuk }\end{array}$ & $23,39 a b$ \\
\hline $\mathrm{E}$ & $\begin{array}{l}75 \% \text { dosis pupuk NPK } \\
\text { majemuk }\end{array}$ & $40,76 \mathrm{~d}$ \\
\hline $\mathrm{F}$ & $\begin{array}{l}100 \% \text { dosis pupuk NPK } \\
\text { majemuk }\end{array}$ & $36,23 \mathrm{~cd}$ \\
\hline G & $\begin{array}{l}\text { 125\% dosis pupuk NPK } \\
\text { majemuk }\end{array}$ & $30,92 \mathrm{bc}$ \\
\hline $\mathrm{H}$ & $\begin{array}{l}150 \% \text { dosis pupuk NPK } \\
\text { majemuk }\end{array}$ & $29,01 \mathrm{abc}$ \\
\hline I & $\begin{array}{l}50 \% \text { dosis pupuk NPK } \\
\text { majemuk }+50 \% \text { dosis } \mathrm{N}, \mathrm{P} \text {, } \\
\text { K tunggal }\end{array}$ & $31,24 \mathrm{bc}$ \\
\hline & $\begin{array}{l}75 \% \text { dosis pupuk NPK } \\
\text { majemuk }+75 \% \text { dosis N, P, } \\
\text { K tunggal }\end{array}$ & $24,19 \mathrm{ab}$ \\
\hline
\end{tabular}

Keterangan: Angka yang diikuti dengan huruf yang sama tidak menunjukkan perbedaan yang nyata menurut uji jarak berganda Duncan taraf 5\%.

\subsection{Bobot Umbi Bawang Merah}

Hasil analisis menunjukkan pupuk NPK majemuk secara signifikan terhadap bobot umbi segar dan bobot umbi kering bawang merah. Berdasarkan Tabel 3, perlakuan pupuk NPK majemuk $75 \%$ berbeda nyata dibandingkan perlakuan lainnya dan memiliki hasil tertinggi dengan rata-rata bobot umbi segar 41,64 g dan bobot umbi kering sebesar 25,27 g. Hasil terendah ada pada perlakuan kontrol rata-rata bobot umbi segar sebesar 24,20 g dan bobot umbi kering sebesar 14,40 g. Perlakuan pupuk NPK majemuk 75\% merupakan dosis terbaik terhadap bobot umbi segar dan bobot umbi kering. Hal ini disebabkan perlakuan pupuk NPK majemuk 75\% merupakan dosis yang memberikan hasil tertinggi pada $\mathrm{N}$-total dan serapan $\mathrm{N}$ tanaman. Penyerapan $\mathrm{N}$ mempengaruhi tinggi tanaman, jumlah anakan, bobot segar umbi, dan bobot kering tanaman (Tambak dkk., 2013).

Berat umbi per rumpun yang diperoleh dinilai masih cukup rendah dari berat umbi per rumpun yang bisa dicapai bawang merah varietas Trisula, yaitu 39,0-93,3 g. Hasil analisis tanah awal juga menunjukkan tanah memiliki tekstur dominan liat yang dapat mengganggu tumbuh dan berkembangnya akar sehingga mengganggu proses pembesaran umbi (Azmi dkk, 2011).

Tabel 3 Pengaruh pupuk NPK majemuk terhadap bobot umbi

\begin{tabular}{llrc}
\hline & \multicolumn{1}{c}{ Perlakuan } & $\begin{array}{r}\text { Bobot Umbi Segar } \\
\text { g/rumpun }\end{array}$ & $\begin{array}{c}\text { Bobot Umbi Kering } \\
\text { g/rumpun }\end{array}$ \\
\hline A & Kontrol & $24,40 \mathrm{a}$ & $14,40 \mathrm{a}$ \\
B & Pupuk N, P, K tunggal & $35,40 \mathrm{bc}$ & $20,40 \mathrm{~b}$ \\
C & Pupuk NPK majemuk 25\% & $29,87 \mathrm{~b}$ & $17,60 \mathrm{ab}$ \\
D & Pupuk NPK majemuk 50\% & $30,27 \mathrm{bc}$ & $18,13 \mathrm{ab}$ \\
E & Pupuk NPK majemuk 75\% & $41,64 \mathrm{~d}$ & $25,27 \mathrm{c}$ \\
F & Pupuk NPK majemuk 100\% & $36,00 \mathrm{c}$ & $21,20 \mathrm{~b}$ \\
G & Pupuk NPK majemuk 125\% & $32,87 \mathrm{bc}$ & $20,13 \mathrm{~b}$ \\
H & Pupuk NPK majemuk 150\% & $32,53 \mathrm{bc}$ & $19,33 \mathrm{~b}$ \\
I & 50\% NPK majemuk + 50\% N, P, K tunggal & $34,07 \mathrm{bc}$ & $20,33 \mathrm{~b}$ \\
J & $75 \%$ Pupuk NPK majemuk + 75\% N, P, K tunggal & $30,87 \mathrm{bc}$ & $18,87 \mathrm{~b}$ \\
\hline
\end{tabular}

Keterangan: Angka yang diikuti dengan huruf yang sama tidak menunjukkan perbedaan yang nyata menurut uji jarak berganda Duncan taraf 5\%. 
Perlakuan pupuk NPK majemuk di atas dosis $75 \%$ yaitu perlakuan pupuk NPK majemuk 100\%, 125\%, 150\%, perlakuan 50\% NPK majemuk $+50 \% \mathrm{~N}, \mathrm{P}, \mathrm{K}$ tunggal, dan perlakuan $75 \%$ NPK majemuk $+75 \% \mathrm{~N}, \mathrm{P}, \mathrm{K}$ tunggal mengakibatkan hasil bobot umbi segar dan umbi kering bawang merah menjadi rendah. Hal ini menunjukkan bahwa pemberian pupuk $\mathrm{N}$ dalam dosis yang tinggi tidak menjamin peningkatan hasil (Hedge, 1988 dalam Natitupulu dan Winarto, 2010), dan justru akan mengurangi hasil panen (Xiang et. al., 2008). Hal lain yang perlu dipertimbangkan adalah ketersediaan unsur hara yang lain, hal ini mengingat pertumbuhan tanaman akan ditentukan oleh ketersediaan unsur hara yang paling minimum (Marschner, 1995 dalam Husnain dkk., 2016).

\section{KESIMPULAN}

Pupuk NPK majemuk berpengaruh nyata terhadap peningkatan $\mathrm{N}$-total, serapan $\mathrm{N}$, dan hasil bawang merah pada Inceptisols asal Jatinangor. Dosis pupuk NPK majemuk 75\% (675 kg/ha) memberikan hasil tertinggi pada kadar N-total tanah yang berkorelasi dengan nilai serapan N. Dosis pupuk NPK majemuk $75 \%$ (675 kg/ha) juga memberikan hasil tertinggi pada bobot umbi bawang merah, dengan bobot umbi segar 41,64 g/rumpun dan bobot umbi kering $25,27 \mathrm{~g} /$ rumpun.

\section{DAFTAR PUSTAKA}

Azmi, C., I. M. Hidayat, dan G. Wiguna. 2011. Pengaruh varietas dan ukuran umbi terhadap produktivitas bawang merah. Jurnal Hortikultura. 2(3): 206 $-213$.

Badan Pusat Statistik. 2018. Produksi Bawang Merah Seluruh Provinsi di Indonesia. https://www.bps.go.id/publication/ 2019/10/07/9c5dede09c805bc383 02ea1c/statistik-tanaman-sayurandan-buah-buahan-semusimindonesia-2018.html.

Balai Penelitian Tanaman Sayuran. 2018. Bawang Merah Varietas Trisula. http://balitsa.litbang.pertanian.go.id ind/index.php/varietas/cabai/36- halaman/628-bawang-merahvarietas-trisula.

Damanik, M. M. B., B. E. Hasibuan, Fauzi, Sarifuddin, dan H. Hanum, Kesuburan Tanah dan Pemupukan. USU Press. Medan.

Fiantis, D. 2014. Morfologi dan Klasifikasi Tanah. Padang: Lembaga Pengembangan Teknologi Informasi dan Komunikasi (LPTIK) Universitas Andalas. Padang.

Hartatik, W., dan J.S. Adiningsih. 2003. Evaluasi rekomendasi pemupukan NPK pada lahan yang mengalami pelandaian produktivitas (levelling off). Dalam Adimihardja, A (Ed.). Prosiding Seminar Nasional Inovasi Teknologi Sumberdaya Tanah dan Iklim. Pusat Penelitian dan Pengembangan Tanah dan Agroklimat. Bogor, 14-15 Oktober 2003. Hal: 17-36.

Husnain, A. Kasno, dan S. Rochayati. 2016. Pengelolaan hara dan teknologi pemupukan mendukung swasembada pangan di Indonesia. Jurnal Sumberdaya Lahan. 10(1): 25 - 36.

Istina, I. N. 2016. Peningkatan produksi bawang merah melalui teknik pemupukan NPK. Jurnal Agro 3(1): 36-42.

Jumini, Y. Sufyati, dan N. Fajri. 2010. Pengaruh pemotongan umbi bibit dan jenis pupuk organic terhadap pertumbuhan dan hasil bawang merah. Jurnal Floratek. 5(2): 164 171.

Kementrian Pertanian. 2011. Lampiran Surat Keputusan Menteri Pertanian Republik Indonesia No. 4580/Kpts/SR.120/11/2011 tentang 'Deskripsi Bawang Merah Varietas Trisula'.

Napitupulu, D., dan Winarto, L. 2010. pengaruh pemberian pupuk $\mathrm{N}$ dan $\mathrm{K}$ terhadap pertumbuhan dan produksi bawang merah. J. Hort. 20 (1): 27-35.

Novizan. 2005. Petunjuk Pemupukan yang Efektif. Agromedia Pustaka. Jakarta.

Purnawanto, A. M. dan Budi, G. P. 2018, Kajian pengembangan bawang merah pada lahan berkadar liat tinggi (Vertisol) 
dengan penambahan pupuk organik. Jurnal Agritech. 10(2): 108-120.

Roosmarkan, A dan Yuwono, N. W. 2002. Ilmu Kesuburan Tanah. Kanisius. Yogyakarta.

Sumarni, N. R. Rosliani, dan R. S. Basuki. 2012. Respos pertumbuhann, hasil umbi, dan serapan hara NPK tanaman bawang merah terhadap berbagai dosis pemupukan NPK pada tanah Aluvial. Jurnal Hortikultura. 22(4): $366-375$.

Tambak, D. G. P., L. A. M. Siregar, dan Rosmayati. $2013 . \quad$ Respons pertumbuhan dan produksi beberapa varietas bawang merah (Allium ascalonicum L.) dengan pemberian kompos limbah kakao pada tanah Inseptisol. Jurnal Online Agroekoteknologi. 2(1): 95-102.

Xiang, Y., J. Ji-yun, H. Ping, L. Ming-zao. Recent advance on the technologies to increase fertilizer use efficiency. Agricultural Science in China. 7(4): $469-479$. 